\title{
ANÁLISES HERMENÊUTICAS NAS PESQUISAS COM CRIANÇAS DE DUAS ESCOLAS DE EDUCAÇÃO INFANTIL DE BELO HORIZONTE
}

\author{
Lúcia Helena Gomes Saraiva* \\ Magali Reis**
}

\section{RESUMO}

Este artigo tem como objetivo analisar o referencial teórico-metodológico da Hermenêutica na pesquisa social e destaca a Hermenêutica Objetiva como possibilidade de interpretação e análise de evidências de pesquisa na área de Educação Escolar. Discute ainda a propriedade desta metodologia na pesquisa com crianças. A metodologia do estudo partiu de uma revisão bibliográfica sobre o tema, reunindo escritos na área de filosofia sociologia e educação. Na sequência foram realizados observações e registros por meio de gravação de aulas na educação infantil, bem como desenvolvemos um modelo de protocolo de análise das evidências que nos pareceu coerente com o que vínhamos pesquisando. Ao final da pesquisa pudemos compreender que a relação da criança com o desenho carece de mediação e que ao reconhecermos a criança como ativa, competente e protagonista de sua história, precisamos reconhecer também que não podemos confundir esta competência da criança como algo que lhe permita descobrir o mundo por si só.

Palavras Chaves: Hermenêutica. Hermenêutica Objetiva. Criança. Infância. Desenhos Animados.

\begin{abstract}
This article aims to analyze the theoretical-methodological reference of Hermeneutics in social research and highlights the objective Hermeneutics as a possibility of interpretation and analysis of research evidence in the area of School Education. It also discusses the ownership of this methodology in research with children. The methodology of the study started from a bibliographical review on the subject, gathering writings in the area of sociology and education philosophy. In the sequence observations and records were made through recording lessons in early childhood education, as well as developing a model of evidence analysis protocol that seemed coherent with what we had been researching. At the end of the research we can understand that the relation between the child and the drawing lacks mediation and that when we recognize the child as active, competent and protagonist of its history, we must also recognize that we can not confuse this competence of the child as something that allows him to discover the world by itself.
\end{abstract}

Key Words: Hermeneutics. Objective Hermeneutics. Child. Childhood. Cartoons.
* Doutoranda em Educação pela PUC Minas, mestre em educação pela mesma universidade. Pesquisadora do Núcleo de Pesquisa Social: Teoria Crítica da Sociedade, Cultura e Infância (DGP/CNPq).

** Doutora em Educação pela Universidade Estadual de Campinas. Docente do Programa de Pós-Graduação em Educação da PUC Minas. Coordena o Núcleo de Pesquisa Social: Teoria Crítica da Sociedade, Cultura e Infância (DGP/CNPq). 


\section{INTRODUÇÃO}

O objetivo deste artigo é apresentar o referencial teórico-metodológico da Análise Hermenêutica na pesquisa social e destacar, neste contexto, a Hermenêutica Objetiva como uma possibilidade interpretativa atual, a qual é muito utilizada na Europa, principalmente na Alemanha.

A Hermenêutica Objetiva é um método utilizado para a investigação das interações sociais e, para isso, toma a palavra em seu sentido mais profundo e analisa as possibilidades que dela se desprendem ou se fecham na interação social. A Hermenêutica Objetiva trabalha com a reconstrução da interação de forma sequencial e fiel aos fatos e falas registrados.

Intentamos refletir sobre o método Hermenêutico, as vantagens e os limites deste enfoque para as investigações sociais. E ainda, mostrar de forma simples, aspectos teóricos e práticos do método, a fim de torná-los claros e acessíveis. Pensamos também na dimensão pública e coletiva do conhecimento produzido, criando espaço para problematizações e discussões, o que o enriquece.

No percurso de uma pesquisa de mestrado realizada com o método, deparamonos com referências teóricas, em sua maioria na língua alemã, país de origem do método. São referências de grande complexidade para a leitura e entendimento, o que somado à escassez de referências nacionais, impõem dificuldades no estudo. Essas dificuldades, portanto, ainda afastam possibilidades investigativas plurais e suas utilizações, sendo esta pluralidade metodológica importante para comtemplar a complexidade envolvida na investigação sociológica.

$\mathrm{O}$ artigo reflete também sobre o desdobramento do método na pesquisa com crianças pequenas. Este enfoque pode representar uma resposta à necessidade atual de encontrar métodos que permitam compreender a ação da criança, seus contextos culturais e históricos para além da descrição. A metodologia, ao ser empregada com crianças, parece-nos bastante completa.

Por fim, o trabalho hermenêutico aqui apresentado, parte também da experiência. Tem como um dos pressupostos a não separação entre teoria e prática; pesquisador e pesquisa. Sujeito e predicado não são separados e a interpretação é vista como um encontro de diferentes perspectivas e sentidos, os quais são equacionados por 
uma interpretação abdutiva em grupo. É desafiador para os pesquisadores, pois instigaos a um cerco ao objeto estudado, procurando analisá-lo em suas múltiplas possibilidades (o que não representa esgotá-lo, pois isso seria impossível), sem o separar em categorias de análise para estudo, o que fragmentaria o estudo e o tornaria vulnerável ao subjetivismo do pesquisador.

\section{METODOLOGIA}

A metodologia Hermenêutica Objetiva, que foi desenvolvida pelo sociólogo alemão Ulrich Oevermann, se dedica a analise das formas de expressões de "textos sociais ${ }^{1} "$, bem como a busca pela compreensão dos sentidos atribuídos pelos atores sociais nessas expressões. Esta metodologia está fundamentada na Dialética Negativa de Theodor Adorno, na sociologia e está vinculada à interpretação sociológica hermenêutica (VILELA, 2010). Por outro lado, na constituição do método, Oevermann (2002) cita que a Hermenêutica Objetiva tomou da teoria da abstração reflexiva de Piaget conceitos que ajudam a explicar sobre a autonomia de um ator na tomada de decisões. O mesmo fez Oevermann (2002), com relação à teoria da abdução de Peirce, para trabalhar na reconstrução de uma cena e reconhecer a melhor compreensão da mesma. Reichertz (2004) cita que também há um apoio na teoria da linguagem de George Herbert Mead e com os conceitos de regra de John Searle. Wernet (2013) faz referências aos conceitos de latente e manifesto, presentes na Hermenêutica Objetiva, tendo similaridade com as funções manifestas e latentes, formuladas por Robert $\mathrm{K}$. Merton e também com o manifesto de um sonho e sua ideia latente proposta por Freud.

Mas, antes de passarmos à conceituação e descrição do método, pontuaremos alguns aspectos históricos que se relacionam à interpretação hermenêutica e que estão na base da Hermenêutica Objetiva.

\section{BREVE HISTÓRICO DA HERMENÊUTICA}

\footnotetext{
${ }^{1}$ Texto social - expressão utilizada por Oevermann para se referir à realidade social utilizada em Klinische Soziologie auf der Basis der Methodologie der objektiven Hermeneutik - Manifest der objektiv hermeneutischen Sozialforschung. Tradução nossa
} 
De origem etimológica grega, o termo "hermenêutica" significa "interpretar", “esclarecer”. Remete à compreensão de um texto para além da aparência perceptível, porém implícita. Segundo Sparemberger (2005), na antiguidade grega já há relatos da existência da hermenêutica. Mas é a partir da exegese bíblica e dos textos jurídicos que ela tem sua continuidade. Santos (2008), através dos seus estudos sobre hermenêutica bíblica, relata que no século III já há produções de textos bíblicos dos escritos do cristianismo primitivo aceitos como hermenêutica.

Desde então, a hermenêutica foi considerada uma arte, ou prática, de interpretação de textos aplicada à teologia, à filosofia, literatura, história. Porém, após os séculos XVIII e XIX, estudiosos como Shleierermacher, Dilthey, Weber, Mannheim, Heidegger, Gadamer, Habermas e Ricoeur iniciaram várias posições teóricas e de diferentes abordagens interpretativas de textos envolvendo a hermenêutica, as quais são objetos de estudo e discussão ainda hoje. (SCOCUGLIA, 2002; WELLER, 2010).

O filósofo alemão Diltlhey (1833-1911) publicou em 1900, um texto intitulado "Surgimento da Hermenêutica". Nesse texto, ele defende a necessidade de criação de um método de pesquisa para as ciências sociais diferente dos métodos adotados nas ciências naturais. Um método que possibilitasse a "compreensão" no lugar da “explicação”. Em sua obra, ele negava a lógica das ciências naturais como capaz de compreender a realidade social, contrapunha-se assim, ao positivismo hegemônico no século XIX. Ele buscava uma cientificidade para a compreensão da ação social, a fim de ir além da interpretação cotidiana e do senso comum.

As reflexões de Dilthey, produzidas entre 1870 e 1910, fundamentam a hermenêutica como um método passível de aplicação sob um rigor científico, capaz de analisar a realidade social, reconhecendo a historicidade dessa realidade (WELLER, 2010). Segundo Scocuglia (2002), Gadamer, em "Verdade e Método", obra publicada em 1960, apontou limites na obra de Dilthey, os quais devem ser entendidos dentro do período histórico dos debates sobre o positivismo nos fins do séc. XIX. Apesar das reformulações colocadas por Gadamer, ele reconhecia a importância de Dilthey na caracterização das ciências sociais como ciência interpretativa e para a ampliação da hermenêutica como forma de conhecimento da sociedade e da história (SCOCUGLIA, 2002).

Já na década de 1950, a pesquisa quantitativa foi o padrão de investigação 
dominante nas pesquisas sociais e sempre houve controvérsias quanto aos métodos de investigação, que foram marcados pela dualidade subjetivismo/pesquisa qualitativa e objetivismo/pesquisa quantitativa. Após a segunda grande guerra, nas décadas de 1960, 1970; com os questionamentos e discussões a respeito do positivismo e do uso da pesquisa quantitativa no campo das ciências sociais e educação, houve maior interesse pela busca de métodos de pesquisas qualitativas. Havia críticas de que as práticas quantitativas mostravam uma visão macroscópica do social e, assim, as práticas qualitativas foram ganhando reconhecimento no preenchimento de lacunas das práticas quantitativas. Outra crítica às pesquisas quantitativas era de que buscavam atender às demandas gerais do mercado, muito utilizada nos Estados Unidos. Por outro lado, as pesquisas qualitativas eram criticadas como meramente subjetivas (WELLER, 2010). A partir dos anos 1980, esse debate começou a ser superado e, atualmente, as pesquisas qualitativas e quantitativas deixaram de serem vistas como opostas, ou melhor, ou pior. Elas se tornam aceitas como formas diferentes e necessárias de se fazer pesquisa social (REICHERTZ, 2004).

Assim, as abordagens qualitativas passaram a ter maior aplicação em ciências sociais devido a possibilitarem pesquisas com métodos interpretativos e focarem contextos mais específicos. No centro desse debate, na Alemanha, a hermenêutica emergiu como aporte teórico-metodológico com mais força. O foco da discussão foi uma crítica sobre os métodos quantitativos, usados especialmente na América do Norte, na medição sociológica (REICHERTZ, 2004). Nesse processo reflexivo, há um destaque para o trabalho conduzido por pesquisadores da Escola de Frankfurt ligados à Teoria Crítica.

Atualmente, a hermenêutica é amplamente utilizada e estudada na Alemanha em vários campos do conhecimento, como a sociologia, a psicologia social, a psicanálise, a educação, com diferentes enfoques teóricos e abordagens interpretativas de texto. Uma dessas abordagens é a Hermenêutica Objetiva, que utilizamos em nosso estudo.

A Hermenêutica Objetiva foi desenvolvida pelo professor Ulrich Oeverman e sua equipe na Universidade de Frankfurt a partir de 1968. Oevermann conduzia uma pesquisa puramente quantitativa sobre "Origem Familiar e Escola". Estudava a correlação entre origem social e problemas de aprendizagem. Segundo Reichertz (2004), a insuficiência dos resultados obtidos levou Oevermann a uma reavaliação do 
método de investigação que utilizava. O pesquisador alemão chegou à conclusão de que necessitariam estudar o meio familiar e compreender os sentidos dos dados levantados. Oevermann e sua equipe começaram a desenvolver métodos de análise e coleta de dados qualitativos até 1970 e começaram a utilizar a hermenêutica ainda na sua forma tradicional para a análise dos dados obtidos (WERNET, 2013).

Segundo Reichertz (2004), Oevermann encerrou o trabalho de desenvolvimento do método, ao qual passou a se referenciar como Hermenêutica Objetiva a partir de 1980, e não se ocupa mais com a justificativa e fundamentação do mesmo, uma vez que o método é consolidado como análise sociológica. Atualmente, desenvolve consultorias, trabalha com o método para a análise de temas políticos atuais, crítica da mídia, significado das religiões, interpretações de pinturas, forma de organização dos serviços policiais a partir de relatórios criminais, teoria das profissões e inovações. Outros pesquisadores que utilizam a Hermenêutica Objetiva buscam novos casos de análise e a ampliação das discussões acerca das implicações teórico-metodológicas da abordagem.

Na área da educação, também ligado à Universidade de Frankfurt, há o grupo de pesquisadores liderados pelo professor Andreas Gruschka, em que são desenvolvidas pesquisas sobre a realidade escolar na Alemanha. Os pesquisadores investigam um conjunto de escolas, com foco de análise na sala de aula, e utilizam sistematicamente a Hermenêutica Objetiva. Ligado a esse grupo alemão, por uma parceria, está o grupo brasileiro "Teoria Crítica e pesquisa empírica", que foi coordenado pela professora Rita Amélia Teixeira Vilela. Atualmente, esse grupo é coordenado pela professora Magali dos Reis.

\section{O MÉTODO HERMENÊUTICA OBJETIVA}

A Hermenêutica Objetiva consiste em uma metodologia de reconstrução interpretativa das interações sociais. Ela fornece um conjunto de técnicas e procedimentos de pesquisa adequados principalmente para o reconhecimento e compreensão das estruturas típicas que caracterizam essas relações (OEVERMANN, 2002). A reconstrução, principal eixo de trabalho realizado pela Hermenêutica Objetiva, busca o entendimento da interação a partir da seleção dos modos de agir dentro da estrutura socializante, ou seja, das escolhas realizadas pelos atores, as quais estão 
marcadas em algum tipo de texto. Busca reconhecer as estruturas de significados latentes, compreendê-las através da reconstrução e revelá-las. O foco desse método não é o significado das ações, ou a sua descrição, seu conceito, mas as diferenças, as tensões e até mesmo contradições entre as intenções que estão contidas nelas. Isso é avaliado através dos textos escritos, protocolos de pesquisa de campo, entrevistas, assim como obras de arte, música, arquitetura, os quais são igualmente textos a serem interpretados (WERNET, 2013).

Para a Hermenêutica Objetiva, as estruturas presentes nas interações sociais possuem implicações latentes em seus enunciados. Essas estruturas se diferem de disposições subjetivas, que são próprias da Hermenêutica Subjetiva ou Psicológica. A metodologia baseia-se na decifração do significado objetivo, o qual está oculto em cada disposição subjetiva ou uma forma de expressão com conteúdo latente (KRAIMER, 2008). A interação opera dentro de uma "autonomia de vida prática" em consonância com a estrutura social (uma sala de aula, uma relação familiar, um posto de trabalho) e pela relação ou assunto que se estabelece entre os atores inseridos nesse texto social.

A "autonomia de vida prática" é permeada pelas regras, que são próprias de cada interação, e pela estrutura social. O conceito de regra difere de convenção e de conhecimento. As convenções são as ações sociais conformadas para cada estrutura socializante, as regras, por sua vez, definem o horizonte de alternativas e o significado destas alternativas. Convenções pertencem ao conhecimento comum e às nossas expectativas de vida cotidiana. As regras geram ações, permitem que os atores criem ações significativas, mas são aplicadas inconscientemente pelos atores, diferente de regras linguísticas, por exemplo, que são aplicadas de forma consciente (WERNET, 2013).

No desenrolar da interação, essa "autonomia de vida prática" se abre com mais e mais opções de escolhas (KRAIMER, 2008), o que permite que as ações significativas dessas estruturas se rearrajem. Esse rearranjo é o reflexo das escolhas dos atores, ou seja, a seleção do modo de agir dentro do enquadramento social de um para com o outro (OEVERMANN, 2002).

\footnotetext{
${ }^{2}$ Autonomia de vida prática - expressão utilizada por Oevermann para se referir às escolhas realizadas pelos atores dentro de um enquadramento social, utilizada em Klinische Soziologie auf der Basis der Methodologie der objektiven Hermeneutik - Manifest der objektiv hermeneutischen Sozialforschung. Tradução nossa.
} 
Porém, as ações adotadas na prática da vida, no "aqui e agora", são marcadas pelo tempo e pelo espaço e são mais voláteis (OEVERMANN, 2002). Uma vez registradas, gravadas e transcritas, elas se tornam atemporais e menos voláteis. Junto a essas ações diárias, há implicações latentes e inconscientes aos atores ou em termos como um desejo, uma esperança, um conflito, uma fantasia não anunciada (KRAIMER, 2008). Essas implicações são atemporais e podem se manifestar a qualquer momento (OEVERMANN, 2002). E essa manifestação é característica da tensão entre o nível da estrutura socializante e a compentência do ator.

Para exemplificarmos os conceitos abordados até aqui, vamos tomar uma cena fictícia de um aluno com seu professor dentro da sala de aula, conforme figura 1 abaixo. O subespaço da sala de aula é o enquadramento social. Esse enquadramento social e a carga cultural dos atores impõem determinados limites, ou seja, através de uma convenção e o conhecimento desta, o professor deve utilizar uma linguagem mais culta e formal; os alunos devem usar o uniforme adequadamente e portar seu material didático. Esses limites fazem parte da "autonomia de vida prática". Uma saudação cordial e contida entre o professor e o aluno, ao se encontrarem, é um marco funcional que delimita que a aula está para começar, é um marco que aponta para um acordo cooperativo (OEVERMANN, 2002). Com o passar do tempo, a "autonomia de vida prática" é permeada pelas várias escolhas dos atores, as quais estão delimitadas pelas regras. É quando as formas das estruturas se rearrajam. Poderá ocorrer de o cumprimento cordial ceder lugar a um aceno ou uma interjeição simples, como "Oi!", ou a ausência de saudação, ou o aluno pedir a caneta do professor emprestada, etc. É a partir dessa "abertura na interação" (KRAIMER, 2008, p. 03), o que no cotidiano pode parecer trivial, que a Hermenêutica Objetiva inicia seus procedimentos de análise em busca do conteúdo dessas interações; tenta reconhecer os sentidos latentes. Pode ocorrer ainda das falas, ações, gestos, não levantarem suspeitas tão claras, o que deve ser observado pela experiência do grupo de analistas.

\section{Figura 1 - A interação dentro de um enquadramento social}




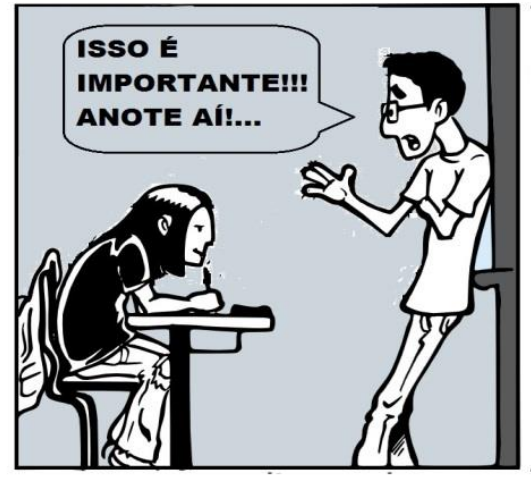

PARA OS ATORES:

ATENÇÃO NAS INFORMAÇÕES

PRINCIPAIS DAS FALAS

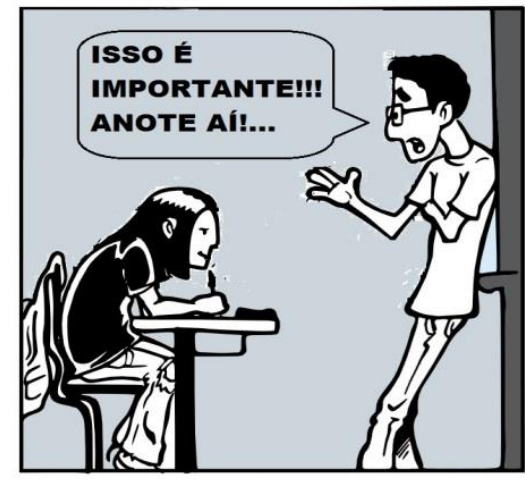

PARA A HERMENÊUTICA OBJETIVA: CONVENÇÕES, REGRAS

(ESPECIFICAS, UNIVERSAIS E DE COMPETENNCIA), CONHECIMENTO, IMPLICACÕES DE LATÊNCIA

Fonte: Adaptação própria

Um ponto importante, durante a fase da interpretação, refere-se justamente às perspectivas dos intérpretes, as quais devem ser críticas. A análise deve começar pelo conhecimento tácito diante das regras que podem estar em operação sobre os atores; ou seja, no reconhecimento daquilo que acomete o ator e que se manifesta através de seus aspectos comunicativos. Charlton (1994 ${ }^{\mathrm{a}}$ ), Kraimer (2008), Wernet (2013), concordam que na análise, se começamos pela teoria, o conhecimento tácito perde força. A formulação de um resultado numa linguagem teórica deve constituir-se no último passo.

\section{PROCEDIMENTOS DO MÉTODO HERMENÊUTICA OBJETIVA}

A Hermenêutica Objetiva é um método de pesquisa com uma exigência metodológica particular. Mas, apesar de num primeiro instante parecer uma prática difícil, essas exigências deixam o método relativamente fácil para sua aplicação, conforme será explicado a seguir.

\subsection{Registro das Evidências da Pesquisa}

Segundo Wernet (2013), de uma forma geral, na Hermenêutica Objetiva não há um procedimento padrão para a coleta dos dados. O método é tratado como flexível e aberto ao estudo dos mais diversos objetos sociais e, por isso, uma estratégia de abordagem prévia deve ser discutida com pesquisadores mais experientes conforme o caso. 
Oevermann (2002) afirma que os dados poderiam ser analisados a partir de uma anotação de campo, mas recomenda a gravação em áudio como um método mais factual e menos propenso ao subjetivismo do pesquisador. Oevermann justifica que o apoio na memória pode não ser tão substancial quanto a gravação, enquanto o olhar e a memória humana são seletivos. Da mesma forma, a gravação em vídeo também pode se sujeitar à seletividade e ao subjetivismo do pesquisador, pois o mesmo poderá direcionar a câmera para um ponto específico da cena em detrimento de outro. Importante também é o pesquisador estar familiarizado com a tecnologia dos instrumentos de coleta de dados que irá utilizar e, se possível, possuir instrumentos sobressalentes para a coleta dos dados, pois é comum se deparar com situações inusitadas (FLICK, 2009).

$\mathrm{Na}$ estratégia de abordagem, deve-se discutir sobre a condição do pesquisador também estar sujeito às regras e convenções da interação social. Assim, é importante estar atento para que sua presença não gere camadas de latência que se sobreponham ao objeto de pesquisa, principalmente na condição de observador participante.

\subsection{Transcrição das gravações}

Esta etapa da pesquisa consiste em transcrever as falas das gravações do áudio ou vídeo, através de uma forma metódica, gerando o protocolo que será o material empírico de análise. Esta tarefa consiste, assim, na preparação do texto, principal elemento da Hermenêutica Objetiva. Este trabalho pode ser realizado por um único pesquisador ou por uma equipe conforme o volume de dados a transcrever. Neste estudo percebemos que os dados devem ser ouvidos tantas vezes quanto necessário, para que o pesquisador possa se familiarizar com as vozes dos atores e assim identificá-los corretamente; só então, se inicia o processo de transcrição. A transcrição deve ser fidedigna às falas (WERNET, 2013) e mantem-se as gírias, apelidos, atos-falhos, erros de pronúncias, contrações de palavras, etc. do áudio. Nenhum dado pode ser acrescentado às falas, senão como nota explicativa acerca da gravação, como uma fala sussurrada, rispidez, grito, bocejado, etc.

Conforme a interação social pesquisada, ruídos externos provocados por equipamentos e maquinários, falas externas aos cenários, quedas de objetos, podem tornar esse trabalho castigador ou mesmo impossível. No caso de pesquisa com 
crianças, pode ocorrer das falas ficarem sobrepostas, o que requer especial atenção para que todas elas sejam compreendidas e transcritas adequadamente. Com crianças, também se aumenta a dificuldade para a identificação de gênero e o caderno de campo se torna um instrumento auxiliar importante, pois nele pode conter informações que muito auxiliam nas identificações dos atores e demais ruídos. Mais adiante, na seção 0, retomaremos esses itens, os quais muitos foram percebidos na nossa experiência.

\subsection{Protocolo}

Como já dito, o protocolo é o principal elemento utilizado pela Hermenêutica Objetiva, pois consiste no texto, através do qual uma cena social é registrada, analisada e, suporta assim, a materialidade, ou a objetividade da análise. Não há nenhum método no campo da pesquisa qualitativa que seja tão estritamente vinculado ao texto como o ponto central de referência na prática hermenêutica (WERNET, 2013).

O protocolo e se inicia por um cabeçalho, no qual deve conter: quantas pessoas estão na cena de interação, quantos pesquisadores, se são participantes, data e horário das gravações, tempo total de gravação e marcador cronológico que sirva de orientação para os analistas. A seguir, toda a cena registrada no áudio é transcrita. Cada fala deve ter seu ator identificado corretamente, o qual preferencialmente terá um codinome para a preservação das identidades.

\subsection{Os procedimentos da análise}

Ao aproximarmos do protocolo para análise, haverá três obstáculos que precisam ser superados pelo grupo de analistas. Em primeiro lugar, é necessário recusar a pressão para agir que sempre domina a vida cotidiana e que pode interromper prematuramente todo um processo de análise. Uma única palavra pode demandar grande intervalo de tempo. Em seguida, é necessário certificar-se de que os analistas não se apeguem a quaisquer extremismos ideológicos ou preconceituosos. Segundo Reichertz (2004), Oevermann não reporta como isso pode ser alcançado. Finalmente, os analistas devem possuir conhecimento da linguagem da interação social em análise. Weller (2010) acrescenta que os analistas devem possuir domínio de conhecimentos teóricos e do tipo 
do contexto social sob análise.

Segundo Reichertz (2004), não há uma abordagem única para a interpretação Hermenêutica Objetiva de textos. Reichertz (2004) lembra que há três abordagens. Mas, Wohlrab-Sahr (2003; apud WELLER 2010) pontua que as análises não podem se distanciar dos princípios fundamentais da Hermenêutica Objetiva, o que garantirá a validade da interpretação e que serão apresentados mais adiante (vide p.59).

Uma das abordagens de análise Hermenêutica Objetiva referidas por Oevermann et al. (1979) citado por Reichertz (2004), considera a análise detalhada de um texto, em que o conhecimento do contexto e também da pragmática de um tipo de interação, são apresentados com antecedência e são tidos em conta na análise.

Outra abordagem, segundo Oevermann et al. (1980) citado por Reichertz (2004) consiste na interpretação completa dos dados objetivos sociais de todos aqueles que participaram em uma interação, antes de qualquer abordagem ser feita no texto a ser analisado.

A terceira abordagem faz a análise seqüencial de cada contribuição individual dos atores para uma interação, passo a passo, sem apresentar previamente o contexto da interação. Segundo Oevermann et al. (1979) citado por Reichertz (2004) esta é a variante mais exigente e constitui o núcleo da Hermenêutica Objetiva, uma vez que é fortemente orientada para as premissas metodológicas do conceito global.

Porém, Oevermann (2000) citado por Kraimer (2008), nos traz que há duas abordagens possíveis conforme a necessidade da pesquisa: uma abreviada e outra metodologicamente explícita. Em Oevermann (2002), também encontramos a explicação destas abordagens.

A Associação Hermenêutica Objetiva alemã (Arbeitsgemeinschaft Objektive Hermeneutik) cita em sua página que o nível de desenvolvimeto da Hermenêutica Objetiva evoluiu consideravelmente nas décadas seguintes ao seu lançamento. Como introdução ao estudo da Hermenêutica Objetiva, a associação recomenda os seguintes documetos: OEVERMANN, ULRICH (2002): Klinische Soziologie auf der Basis der Methodologie der objektiven Hermeneutik (Manifest der objektiv hermeneutischen Sozialforschung) e OEVERMANN, ULRICH (2001): Strukturprobleme supervisorischer Praxis. Exemplarische objektiv hermeneutische Sequenzanalyse zur Überprüfung der Professionalisierungstheorie. (Forschungsbeiträge aus der Objektiven Hermeneutik, 
Bd. 2. Hg. von ULRICH OEVERMANN; et al). A leitura do documento OEVERMANN, ULRICH; et al. (1979): Die Methodologie einer 'objektiven Hermeneutik' und ihre allgemeine forschungslogische Bedeutung in den Sozialwissenschaften. In: HANSGEORG SOEFFNER (Hrsg.) Interpretative Verfahren in den Sozial- und Textwissenschaften. Stuttgart: Metzler, S. 352-434 deve ser realizada posteriormente aos dois primeiros documentos.

Segundo a pesquisadora brasileira Rita Amélia Teixeira Vilela, as duas primeiras abordagens citadas por Reichertz, seriam aplicadas "[...] em textos oriundos de pesquisa de cotidiano [...]"3 e não receberiam o atributo "objetiva". Assim, compreedemos que esta questão das abordagens, citadas para a prática da Hermenêutica Objetiva, demanda uma maior investigação em outros estudos. Em nossos trabalhos, ainda não conseguimos esgotar tal questão, devido as publicações nacionais e alemãs, que tivemos acesso, não abarcarem claramente as abordagens possíveis para a Hermenêutica Objetiva.

Charlton (1994a), sem abrir mão de um rigoroso cumprimento dos princípios pontuados pela Hermenêutica Objetiva, sugere uma análise em que o protocolo seja dividido em cenas, as quais ele chama de Interacto, na lingua espanhola, ou Interakt, na lingua alemã. São trechos de interação onde os analistas buscam a estrutura do caso analisado, ou identificação das regras que operam. Essa leitura é feita num primeiro Interacto e posteriormente verifica-se a recorrência nos demais. Caso haja repetição, aceita-se isso como uma confirmação da estrutura do caso. Mas Charlton afirma que se pode proceder com a análise de outras maneiras, desde que não violemos os princípios fundamentais da análise Hermenêutica Objetiva. Oevermann (2002) pontua que na prática da análise Hermenêutica Objetiva pode se trabalhar desta forma, com o que ele chama de "critério de contraste máximo", que consiste em analisar trechos bem definidos de protocolos sucessivamente, onde se busca um contraste que permite reconhecer a conformidade da estrutura em análise.

Em nossa experiência, percebemos que o ambiente da análise deve consistir de um local onde os analistas tenham liberdade para se expressarem e que seja garantida a privacidade do texto e dos atores sociais envolvidos. O ideal é um espaço que se possam fazer anotações, gravar em áudio todo o processo analítico e buscar desta forma garantir

\footnotetext{
${ }^{3}$ Anotação manuscrita inserida na revisão da dissertação após apresentação à banca examinadora.
} 
que a interpretação produzida não sofra intervenções. O procedimento da análise gera certa tensão, o que implica formar um grupo com pelo menos três analistas, dos quais pelo menos um tenha maior experiência com o método, mas todos devem conhecer os princípios fundamentais da Hermenêutica Objetiva.

A análise é iniciada com a distribuição de uma cópia do protocolo para cada analista. Quando permitido, conforme a variante de análise, faz-se a leitura da interação social (crianças assistindo a um desenho animado, uma aula de matemática, uma reunião de pais na escola, entre outros) a partir do protocolo. Ainda conforme a variante de análise, outras informações podem ou não serem apresentadas (primeiro dia de aula, conflituoso, professor ou aluno novato, autoritarismo, preconceituoso, entre outros).

Wernet (2013) aponta quatro princípios fundamentais para a interpretação com Hermenêutica Objetiva:

a) Liberdade ou independência de contexto,

b) Sequencialidade,

c) Aceitar firmemente o significado literal de um texto (literalidade), e

d) Extensividade (substancialidade).

Segundo Wernet (2013), parece estranho a análise de uma interação social não desejar saber informações sobre o contexto antecipadamente, já que este gera influências nas regras que regem a interação, bem como é influenciado por essas mesmas regras. Mas o que ocorre é que esse princípio visa garantir que o analista não se impregne com o contexto e passe a correr o risco de ignorar falas, ou relativizá-las, ao aceitar que elas pertençam claramente ao cotidiano daquele contexto. Este princípio obriga o intérprete a contrastar sistematicamente a fala manifesta com o seu significado (particular do ator) na sequência do texto (WERNET, 2013).

Wernet (2013) cita que para uma análise, da qual os analistas possuem informaçoes sobre o contexto, o exercício consistirá em formular cenários que não se aproximam do contexto conhecido e que suportam as falas da interação de maneira natural. Ou seja, desconstrói-se o cenário já conhecido da interação em análise. É o caso, por exemplo, quando já sabemos que se trata de uma análise de sala de aula, ou de uma reunião pedagógica, entre outros. 
$\mathrm{Na}$ variante mais exigente da Hermenêutica Objetiva, portanto sem pistas sobre a interação social, o analista segue com a leitura a construir cenários e contextos em que os aspectos comunicativos da interação parecem se encaixar. Esses aspectos, como as falas, podem sugerir que se trate de um diálogo entre mãe e filho, por exemplo. À medida que o texto avança, as hipóteses são aceitas ou recusadas, e isso facilita reconhecer trechos de conversas que não são próprios para este tipo de interação social. O analista, que acreditava tratar-se de um diálogo entre mãe e filho, poderá perceber que, à medida que prossegue com a análise, na verdade trata-se de um adulto a conversar com um idoso, como se este fosse uma criança. A análise fica livre de preconceitos e expressões cotidianas não são negligenciadas (HEINZMANN, 2005). Somente ao término completo da análise, ou após um conjunto de análise de interações em que há estruturas reveladas, o contexto pode ser apresentado, o que certamente se alinhará com o contexto percebido na análise até então. Noutras palavras, o contexto real suporta as mesmas estruturas do contexto imaginado na análise, sem necessariamente ser o mesmo contexto.

A leitura do protocolo deve ser realizada sob o rigor da literalidade. Este princípio é uma forma de fixar a atenção do analista aos fatos, no caso, o que está no texto. A literalidade ajuda o pesquisador a não suavizar o que está escrito e entender que o ator deseje dizer algo diferente do que realmente está dito, ou escrito. Para a Hermenêutica Objetiva, nada é por acaso. Mesmo a mais simples palavra pode conter algo de importante a ser descortinado, como um ato-falho, por exemplo, em que uma palavra, num incidente, é substituída por outra e causa geralmente risos ou desconforto entre os atores. E somente o texto tem essa característica própria, como uma base de dados, que pode ser acessível a qualquer momento, ao contrário de uma suposição sobre o que o ator possa ter pensado na cena analisada.

Como a Hermenêutica Objetiva busca revelar as implicações latentes de um enunciado - sua estrutura objetiva de significado, parece natural a importância em seguir um caminho preestabelecido nessa busca, em vez de seguir aleatoriamente. Assim, a sequencialidade aponta que o melhor caminho a percorrer é a ordem natural do texto. Muitos benefícios decorrem dessa prática, a qual recomenda a leitura linha a linha, às vezes palavra a palvra, ou uma frase. Percebemos, na nossa experiência, que essa leitura acaba por considerar, ora uma frase inteira, ora uma linha realmente, ora uma única 
palavra, ora um conjunto de frases que expressem uma semântica mais clara. Mais uma vez, prevalece a experiência do grupo de analistas.

Oevermann (2002) recomenda o início a partir da primeira linha do protocolo, ou a partir de uma saudação, já que esta é um marco onde se espera uma cooperação recíproca. Decorre que a ação humana é um processo constante de escolha e, mesmo que o ator não se decida, o resultado será uma decisão. Isso é um reflexo do dinamismo entre as liberdades e as limitações da vida real na produção de rotina. A análise sequencial revela um processo, a cadeia da lógica da interação entre as falas e as ações selecionadas pelos atores dentro do enquadramento social, o qual apresenta um rol de opções com maior ou menor viabilidade de escolha. A sequencialidade ajuda o pesquisador a acompanhar esse processo de escolha e compreendê-lo.

A reconstrução dessa cadeia seletiva de atos e falas, o que só pode ser realizado através da sequencialidade, revela a estrutura do caso analisado. Isso se deve ao fato que, para a Hermenêutica Objetiva, ao caminhar pelo texto na mesma sequência em que o fato ocorreu, é esperado que o investigador acompanhe as mesmas regras de produção da interação em que esta se desenvolve. E quanto mais se avança na análise sequencial, mais se aproxima do conhecimento sobre o contexto da interação dentro da estrutura social estudada; e mais se desvenda as implicações latentes de um enunciado.

Por último, a extensividade caracteriza-se pela dialética entre a particularidade e a generalidade (WERNET, 2013). A partir dessa dialética, Wernet (2013) e Kraimer (2008) argumentam que é possível trabalhar em um pequeno segmento de texto e analisá-lo com detalhes extremos. Segundo esses pesquisadores, pequenos fragmentos de textos sempre representam também algo geral da realidade social. Ou seja, um pequeno trecho de texto ou mesmo uma única palavra, pelo menos em princípio, podem possuir substância o suficiente para representar a completude do texto. Mas Wernet (2013), em contraste, afirma que, quando todas as partes de um texto são incluídas em uma interpretação, o analista tem menos chances de deformar o signifcado de um texto e mais oportunidades de se confrontar com implicações latentes. A extensividade consite em tentar esgotar as possibilidades de significado e de sentido de uma expressão.

Com a extensividade, assim como na literalidade, o analista deve se ater mesmo à mais simples palavra, isso se deve ao fato que os atores de uma interação social 
geralmente não se atêm profundamente em todas as partes de uma conversa cotidiana, pois é dado maior atenção às instruções principais do diálogo. Na análise de um texto, o nível com significado latente pode ser mais facilmente detectado nas partes de um texto que ganham menos atenção em conversas cotidianas. Com a extensividade, a interpretação procura aprofundar-se, mais que ampliar-se superficialmente; e a contribuição individual de cada analista do grupo é considerada. É importante que os membros do grupo formulem hipóteses numa tentativa de encontrar um sentido lógico para a situação registrada. À medida que se avança no texto, elementos do próprio texto definem a recusa ou permanência das hipóteses formuladas.

Com a prática da extensividade, e pelo princípio definido pela "regra do poupar", o método tenta se certificar que a interpretação se baseie no próprio texto e não em concepções pré-estabelecidas e subjetivas sobre o caso em estudo. A "regra do poupar" impõe que os analistas devem se ater às possibilidades e circustâncias evidentes no texto, sem se ater a supostos motivos para a ação. Com esta regra, as hipóteses que se desalinham com os dados encontrados no protocolo até o determinado ponto, são recusadas.

Na prática, não se pode correr com a leitura e se deve analisar pacientemente cada trecho do texto. Analistas menos experientes podem não resistir à tentação em saber o desfecho das hipóteses formadas durante a análise e acabam por correr os olhos mais adiante no texto em busca de uma confirmação da hipótese que lhe parece mais provável. Essa prática deve ser evitada. (WERNET, 2013).

Em suma, enquanto os atores estão mais atentos com as ordens e informações principais das falas na interação social, os analistas estão mais atentos com as estruturas de significados latentes desse diálogo. E, para isso, eles precisam partir de uma perspectiva diferente daquela que os atores adotam no cotidiano. Esses princípios da Hermenêutica Objetiva ajudam os analistas a se posicionarem para que possam obter tais perspectivas (WERNET, 2013). Para nós, o processo de interpretação, independente do método, envolve um "autoexame" do intérprete. A Interpretação já não é mais vista como o resultado de um posicionamento distante que gera uma visão e interpretação imparciais, mas como um diálogo, onde se encontram diferentes perspectivas (WERNET, 2013).

Em nossa experiência, esses princípios são como valores estratégicos, os quais 
orientam o pesquisador a buscar com que a Hermenêutica Objetiva cumpra seu papel. Parece-nos impossível atribuir maior importância a algum deles e, na prática, é difícil exercê-los isoladamente, o que vulnerabiliza todo o processo da análise. A Hermenêutica Objetiva, assim como outros métodos de pesquisas, possui um grau de incerteza. Wernet (2013) afirma que o método da Hermenêutica Objetiva aponta para a declaração de princípio de validade e isso não significa sugerir que suas interpretações atingem uma verdade absoluta, ou um ponto de vista imparcial; significa apenas que o método valoriza muito a possibilidade de controlar a interpretação. A análise final obtida pelo grupo não é um consenso, mas a melhor compreensão das provas encontradas no texto.

\section{LIMITES DO MÉTODO HERMENÊUTICA OBJETIVA}

Há implicações que são apresentadas como limites da Hermenêutica Objetiva, as quais podem se referir justamente ao que é central para ela. Vejamos:

Há uma necessidade de elevada alocação de pessoas com consequentes custos para a realização dos encontros para as análises. As condições de vida atuais mantêm, muitas vezes, as pessoas com agendas de trabalho múltiplas e sobrecarregadas. Em função disso, pode haver dificuldade para se formar e manter um grupo de analistas e formação. No entanto, esse alto custo com pessoas e tempo é compensado pela riqueza do conhecimento que se produz (FILP, 1994).

Outro ponto crítico é o forte apelo ao viés da análise para com o ato da fala. Muitos pesquisadores questionam que, nas gravações feitas somente em áudio, toda uma linguagem gestual, entonação de voz e emoções podem se perder nas transcrições. Charlton (1994b) aponta que o tom de voz é de grande importância para a análise da interação e, através das entonações das mesmas, uma gama de possibilidades se abre para a interação e consequentemente para a análise. Por isso, é importante que sejam feitas descrições e observações nos protocolos sobre as entonações de voz e gestos.

No caso dos gestos, Charlton (1994b) acrescenta que toda linguagem (oral, gestual, emotiva) atua sobre aquele que recebe a fala e também sobre aquele que fala. Os gestos e a fala estão contidos em uma mesma linguagem. Ao citar Oevermann, ele argumenta que se pode captar na linguagem falada toda a ação. E isto é um pressuposto 
fundamental para a Hermenêutica Objetiva. Assim também é com as emoções, que são gestos sociais. No caso de um gesto discordante com a fala, por exemplo, isso pode ser captado durante a análise, porque com certeza a contradição aparecerá na própria interação, ainda que em outro trecho da análise e do protocolo.

Algumas dúvidas na análise podem encontrar respostas amparadas em um consistente caderno de campo, que contenha observações claras sobre a interação pesquisada. Mesmo que faltem algumas informações, ou que tenham ocorrido dificuldades, ou incidentes que danifiquem os dados durante a coleta, Oevermann (2002) afirma que, para a análise, não há dados ruins, há análise mal feita e que o primordial é que se atenha ao protocolo, ao que está no texto.

Wernet (2013) assinala que outra dificuldade do método seria a falta de procedimentos para instruir pesquisadores inexperientes na coleta de dados e na condução do trabalho de campo. Essa falta de instrução de procedimentos de organização da pesquisa se deve ao conceito de que a Hermenêutica Objetiva é um processo aberto, não padronizado de investigação, e que deve ser ajustado para cada pergunta de pesquisa. Mesmo dúvidas simples, como "quantos casos se deve examinar?", não podem ser respondidas no geral. Para uma determinada nova pesquisa, deve se obter conselhos de pesquisadores mais experientes, procurar cooperação do grupo de analistas e fazer leituras de estudos empíricos semelhantes à sua questão de investigação.

Apesar de ser referido por Oevermann como possível, as análises de vídeos, fotografias e imagens não possuem, ainda, uma clara instrução de procedimentos segundo Wernet (2013). Muitos pesquisadores que utilizam a Hermenêutica Objetiva trabalham com essas linguagens na Alemanha e há uma demanda importante de desenvolvimento metodológico. Atualmente é crescente o interesse pelo estudo da imagem, os quais desempenham importante papel nas abordagens qualitativas. Wernet (2013) afirma que precisa haver mais estudos para o desenvolvimento de metodologias adequadas de análise, principalmente nas análises de vídeo.

\section{A HERMENÊUTICA OBJETIVA COM CRIANÇAS}

\subsection{Sobre como escolhemos o método}


A pesquisa científica com crianças é crescente hoje no Brasil. Apesar de já haver uma tradição de estudos sobre a infância durante todo o século $X X$, essas não consideravam a criança como sujeito, mas como objeto de pesquisa. Segundo Soares (2006), foi a partir da década de 1980 que houve um reposicionamento da criança, quando sociólogos da infância defenderam a necessidade de considerá-las como atores sociais. Esse reposicionamento despertou o desejo de conhecer o ponto de vista da criança e fez com que pesquisadores buscassem novas formas de investigação. Anteriormente, era sempre o adulto quem falava por ela.

Cruz (2008) também assinala que esta nova construção de pesquisa começou a ser desenvolvida apenas nas últimas décadas. Apesar desta nova construção de pesquisa com crianças, muitos estudos ainda preferem recorrer aos adultos, pais ou familiares para obter informações. Realizar a pesquisa "com crianças", e não "sobre as crianças", ainda é pouco predominante. A pesquisa com crianças, portanto, carece de metodologias.

Pesquisadoras da infância como Campos (2008) e Rocha (2008), questionam, em muitos estudos realizados, se estamos conseguindo inserir as crianças e ouvi-las efetivamente. Assim, buscarmos formas de ouvir as crianças era também nosso desejo, e é nessa perspectiva que se insere esta pesquisa. O que nos movia era buscar um método que viesse a acrescentar para os estudos do grupo de Pesquisa da Infância e do grupo de Teoria Crítica, bem como nos possibilitar o encontro de uma maneira de ouvir as crianças; e o mais importante: que trouxesse benefícios para elas. Somente assim, a pesquisa com crianças, utilizando a Hermenêutica Objetiva, poderia contribuir através de uma forma de pesquisar que trouxesse uma compreensão dos sentidos que elas dão ao mundo.

Quando se tratam de crianças menores de seis anos, essas pesquisas são ainda em números mais insuficientes. Muitos pesquisadores refutam este trabalho e se justificam com o argumento das dificuldades de coleta de dados e no estabelecimento de um contato verbal com elas. Mas as crianças ainda pequenas são capazes de entender as nuances dos processos de interação, os quais vão além do ato da fala, e pressupõem a compreensão e a atribuição de significados. Para Charlton (1994a), na interpretação Hermenêutica Objetiva, os anciãos, as crianças, e os adultos são tratados do mesmo modo, pois entram no mesmo sistema de regras da interação e assim são todos tratados como pessoas "competentes". Charlton faz a comparação com uma criança que decide tocar piano e que talvez não o faça como um adulto, 
mas entra nas mesmas regras do instrumento para tocá-lo.

Mas Charlton (1994a) aponta que essa condição da criança se refere apenas ao processo de análise sob a ótica do sistema de regras. Já em relação à organização de uma pesquisa, na nossa experiência, percebemos que há especificidades para a coleta de dados, aproximação no campo, relacionamento com as crianças e com os adultos à sua volta. Leite (2008) rastreou várias dissertações e teses brasileiras, as quais tinham a criança como foco de pesquisa, e seu estudo reforçou a necessidade de construirmos estratégias específicas de abordagens nas quais as crianças tenham o lugar de depoente privilegiado. É importante darmos atenção a vários aspectos relacionados à criança ao buscar ouvi-la, como o contexto onde a fala se organiza, e à sua linguagem.

Nesse sentido, Reis (1997) acentua que a linguagem da criança se faz além do ato da fala, mas também pelo choro, gestos, sorrisos, e olhar. As crianças se comunicam muitas vezes por acenos com a cabeça ou murmúrios, por exemplo, uma expressão "hmm", que somente a observação do pesquisador, durante a coleta de dados, poderá compreendê-los. Muitas vezes, as crianças comunicam-se também pelo silêncio. Assim, durante a análise, esses relatos poderão ser buscados no caderno de campo para ajudar na correta interpretação.

Rocha (2008) pontua que a falta de atenção às linguagens da criança podem gerar problemas metodológicos, como limitar a compreensão que podemos alcançar delas. Assim, a pesquisa com a criança vai muito além de entendê-las num sentido cognoscível, mas também é compreendê-las, compartilhando com elas profundamente experiências do seu ambiente.

Campos (2008) assegura sobre a pertinência de se ouvir as crianças e compreender o ambiente em que ela convive. A autora cita pesquisas em que crianças foram observadas em vários espaços de convivência e demonstraram comportar-se de formas diferentes na escola e na família.

Além da atenção com a linguagem da criança, o ambiente e os adultos em volta dela, Rocha (2008) sugere atenção também na relação com o pesquisador. O pesquisador, sendo adulto, traz inerente consigo traços presentes das relações geracionais, como as de poder. É importante tentar diminuir comportamentos de poder que possam trazer constrangimentos às crianças. A base para a interação com elas é a troca. Uma postura de colocar-se no lugar do outro e compartilhar.

“[...] não só como fonte de orientação para uma ação, mas sobretudo como forma de estabelecer uma permanente relação comunicativa - de diálogo intercultural - no sentido de uma relação que se dá entre sujeitos que ocupam diferentes lugares sociais." (ROCHA, 2008, p.47) 
Ainda, é importante que o pesquisador se oriente por uma perspectiva da infância, além de social, também histórica, dando atenção aos contextos vividos pelas crianças, que desvele falsas ideias de infância como fenômeno natural. Considerar não uma infância, mas as infâncias. Como coloca Dornelles (2008), aquela que é superprotegida e tecnológica, aquela que é abandonada e armada, as infâncias ricas e pobres. A visão de uma infância homogênea e neutra, pautada em idealizações, mascaram e negam as crianças reais.

Em nosso acervo bibliográfico encontramos alguns autores que têm ou apontam estudos sobre a infância com a utilização da Hermenêutica Objetiva. Entre eles, citamos o Prof. Dr. Klaus Kraimer (2008) da Universidade de Ciências de Saarland que apresenta e transcreve, como exemplo, o protocolo da "História do Sapato", na qual é analisada a interação entre o professor e uma criança com seis anos de idade durante uma atividade em que se objetivava ensinar a dar laços nos sapatos, disponível na coleção dos trabalhos feitos por Ulrich Oevermann. Liza Heinzmann (2005), na sua tese em psicologia, a utiliza sob a orientação do Prof. Dr. Michael Charlton da Universidade Freiburg para analisar a interação de uma criança que demonstrava agressividade. A universidade alemã de Magdeburg tem disponível, em seu acervo eletrônico, um recorte de um livro em que apresenta uma interação familiar, retirada do acervo de Ulrich Oevermann, na qual uma criança apresenta medo pronunciado de furadeira eletromecânica. Estas publicações nos tranquilizaram quanto à assertividade do método. Há também publicações do Prof. Dr. Michael Charlton (1994a), que trabalha com análise Hermenêutica Objetiva em estudos sobre a influência dos meios de comunicação de massa sobre a identidade das crianças e análises das interações de mães com seus bebês.

\subsection{O registro das evidências da pesquisa, a transcrição e o preparo do protocolo.}

Para registrarmos os dados utilizamos um gravador de áudio profissional, uma câmera fotográfica e um caderno de campo. Para exibirmos os filmes, utilizamos um computador portátil conectado a uma TV, o que era feito na sala de aula. No decorrer dos trabalhos, percebemos que seria melhor se utilizássemos pelo menos dois gravadores de áudio, tendo em vista que isso forneceria uma segunda fonte, de forma a 
facilitar a compreensão das falas. O uso da câmera fotográfica pelas crianças foi para um apoio à nossa memória e, além disso, um facilitador da expressão das crianças e uma forma de ampliar nossos pontos de vista. O acervo fotográfico gerado é passível de análise, pois, conforme afirma Wernet (2013), a Hermenêutica Objetiva pode ser usada com outras metodologias adicionais.

Com a transcrição, geramos o protocolo, que é o elemento central para a análise Hermenêutica Objetiva e deve ser um instrumento facilitador para a condução do trabalho dos analistas. Porém, não há normatização para seu preparo e, novamente, prevaleceu o experimento e prévio aprendizado do grupo de análise com base em trabalhos anteriores.

O primeiro protocolo exposto para análise seguiu o padrão corrente utilizado pelo grupo Teoria Crítica e Pesquisa Empírica. Porém, na sua construção, um conjunto de dúvidas e problemas surgiu com relação à identificação dos atores e apontamento das falas. Entre as crianças do grupo que analisamos, foi comum pronúncias com troca de letras, palavras incompletas, emissão de ruídos onomatopeicos. Como transcrever essas expressões adequadamente? Como escrever e comentar o que as crianças falavam ou expressavam?

Havia uma disputa entre as crianças no grupo pesquisado: quem fala primeiro, quem segura o microfone, quem fica mais perto. Enfim, não tivemos uma fala, mas várias e quase todas ao mesmo tempo. E mesmo depois que uma criança falava, foi comum ficar por perto "conversando" baixinho com o microfone enquanto outra criança falava com a Lúcia Helena.

Abaixo, temos um trecho de protocolo preparado conforme nossa primeira tentativa e semelhante ao modelo de uso corrente no grupo Teoria Crítica e Pesquisa Empírica. Os códigos CR_FEM_\#\# e CR_MAS_\#\# significam Criança Feminina e Criança Masculina seguidos de uma numeração para identificá-las.

CR_FEM_08: Oi, tudo bem? (fala alto para o microfone)

CR_FEM_04: Oi, tudo bem? (cochicho próximo ao microfone)

CR_FEM_08: Oi, tudo bem? (cochicho próximo ao microfone)

CR_FEM_04: Oooiiii, tudo bem? Belezura pura. (cochicho pausado próximo ao microfone)

CR_FEM_08: Aaaaa....b, c, d (fala com os dedos prendendo o nariz) 
CR_FEM_08 e CR_FEM_04: e, f, g. h, i, j, k, l, m, n, o, p... outras crianças se juntam... q, r, s, t, u, v, w, x, y, z. (tentativa de canto, semelhante à música do VilaSésamo)

Os modelos de protocolos utilizados pelo grupo de analistas, até então, eram de estudos realizados com alunos dos anos finais do ensino fundamental e ensino médio. Nesse grupo, ainda que ocorram falas sobrepostas, ou respostas em conjunto, é relativamente facilitado identificar os atores principais em um trecho de diálogo. As vozes feminina e masculina também se diferenciam; bem como se torna mais fácil identificar o ator pelo timbre, ainda que não tenha sido possível identificá-lo por um vocativo pronunciado por outro ator. Comentários acerca das falas também são em menores quantidades.

O protocolo possui uma metodologia própria para sua leitura. Nesse modelo, muitas vezes, foi difícil estabelecer o final da fala de uma criança e o início de outra devido à superposição de falas; e isso refletiu-se durante a leitura do protocolo. Os códigos CR_FEM_\#\# e CR_MAS_\#\# dificultaram o acompanhamento das falas das crianças, negando assim a sua singularidade, algo que queríamos muito preservar. E ainda foi preciso diferenciar claramente as falas das crianças e as falas do desenho animado ao qual assistíamos. Recorremos então a uma adaptação do protocolo utilizado por Heinzmann (2005). Esse modelo não sanou todas as questões difíceis que tivemos no preparo e leitura do protocolo, mas ajudou muito no estabelecimento dos trechos a serem lidos (linha a linha, palavra a palavra), preservou a singularidade das crianças e trouxe maior conforto para a realização de todo o trabalho.

Abaixo temos o protocolo final adaptado em nosso estudo. Consta da inserção do texto no formato de quadro e a troca dos nomes originais de cada criança por nomes fictícios, o que ajudou a isolar as falas a serem lidas e reconhecermos melhor a especificidade das falas de cada ator. Como no início da pesquisa pretendíamos trabalhar com a identificação dos atores utilizada pelo grupo de analistas do Grupo Teoria Crítica e Pesquisa Empírica, não discutimos a troca de nomes com as crianças. Por isso fizemos a troca aleatoriamente. Esse procedimento é semelhante ao adotado por Charlton (1994a) e Heinzann (2005), ao identificarem os atores por uma letra maiúscula. 
Rodrigo: Sai da frente! (grita com a Kátia que passou à sua frente)

Alberto: Tira aí, sua cabeça daqui! (grita com a Kátia que estava em pé à sua frente)

Professora: Sh... ôh, gente, silêncio!

Kátia: Tia, é o Alberto que tirou o meu lugar (grita para professora)

No cabeçalho do protocolo colocamos uma legenda e um resumo introdutório da cena a ser analisada. Abaixo está a simbologia e a legenda que utilizamos em nosso trabalho.

Minutos de aula:

\section{$\{2: 15 \mathrm{~min}\}$}

Barulhos, ruídos, falas incompreensíveis:

[o ruído de carteira arrastada]

Notas explicativas acerca da gravação:

(fala sacudindo o corpo

\section{lateralmente)}

Citações literais:

"entre aspas"

Pausas nas falas:

Apontamos que a finalidade dessa discussão não é apresentar um modelo de prática, mas trazer a nossa experiência no reconhecimento de que o percurso da pesquisa exige vivacidade, persistência. No nosso entendimento, essas condições impuseram a necessidade de nos flexibilizarmos e nos adaptarmos no encontro com os sujeitos da pesquisa.

\section{CONSIDERAÇÕES FINAIS}

Esta pesquisa é resultado de anos de pesquisa e indagação sobre os processos de escuta das crianças em investigações científicas. Ao conduzirmos nossos esforços para a busca de uma forma de ouvi-las efetivamente na sua singularidade, compreendemos que uma necessidade se impunha, a de pensar uma metodologia que nos ajudasse a reconhecer a linguagem e as ações das crianças em suas particularidades, como se manifestavam e suas implicações nas trocas entre seus pares de idades e com os adultos.

Observamos que das questões iniciais verteram duas ramificações do mesmo estudo. A primeira buscava responder a estas questões iniciais relativas ao reconhecimento das crianças como sujeitos privilegiados de nossas pesquisas, e a segunda nos impunha um aprofundamento de estudos que possibilitasse $\mathrm{o}$ desenvolvimento de um método que nos permitisse confrontar nossos conhecimentos 
sobre o tema infância e ao mesmo tempo que nos conduzisse a uma escuta sistematizada das crianças.

Precisávamos estar confiantes que nos dedicávamos a estudar a compreensão do que era encontrado e ouvido dos mais jovens de uma forma que as acolhêssemos sem posturas invasivas. Hoje, ainda nos é incerto apontar qual projeto foi mais impulsionador.

Retomamos, neste percurso, vários aspectos determinantes da metodologia Hermenêutica Objetiva. Compreendemos que se trata de um método adequado para o emprego em estudos com crianças, se englobados vários aspectos como as falas, gestos, posturas, em uma dialética entre o individual e o coletivo, algo muito peculiar também na criança. Há ainda aspectos que vão além da sua aplicação como metodologia nos estudos com crianças pequenas. O exercício coletivo da pragmática utilizada na interpretação Hermenêutica Objetiva desloca o analista de seu eixo e o faz vivenciar a experiência contida na fala que ele analisa (experimentar a regra).

Esta possibilidade permite que a Hermenêutica Objetiva seja utilizada como instrumento de formação profissional, em licenciatura inclusive, pois possibilita uma avaliação e análise do habitus profissional e uma reflexão sobre nossas experiências.

Esta metodologia, assim como a Teoria Crítica, leva o pesquisador a se expor, a se colocar na pesquisa de uma forma também crítica, erros e acertos são apresentados, mas sem antagonismos, ou melhor e pior, ou seja, novamente em uma dialética que leva ao aprendizado, à aquisição de experiência e exercício da reflexão.

O pesquisador também, ao se deslocar do seu eixo, se confronta com o ator (uma fala) em um mesmo nível e equiparados naquilo que ambos possuem em comum: a condição de humano. Noutras palavras, o pesquisador renuncia à posição de crítico radical (crítica pela crítica) e exerce a alteridade. Há ainda o fato da análise ser realizada em grupo, o que retoma o protocolo por uma perspectiva peculiar, através de uma leitura multidisciplinar amparada nas várias possibilidades que cada analista traz, o que gera um acervo de conhecimento amplo.

Retomamos também as questões iniciais da pesquisa. Compreendemos que a criança é competente para a reflexão e, uma vez que estamos todos em processo de desenvolvimento contínuo, precisamos sim envolvê-las e ouvi-las em nossas relações e decisões. Ao nos deixarmos cercar pelos seus pontos de vista pudemos nos defrontar 
com o novo. Porém, não podemos confundir esta competência da criança como algo que lhe permita descobrir o mundo por si só. Necessitamos compartilhar nosso aprendizado, nosso conhecimento, inclusive o científico, de modo que a criança possa também nos questionar e assim suscitar o novo.

Destacamos que a competência da criança não significa que ela possa receber menos cuidados. Pelo contrário. Sua competência significa que nosso cuidado e atenção com elas precisam ser redobrados, pois elas são capazes de nos compreender, a despeito das limitações e determinações que o mundo impõe. E isso precisa ser feito com o cultivo do espaço para a palavra, pois, sem ele, cederemos espaço para a angústia, para o abandono, seja para as crianças, seja para os professores, para os adultos. Falamos de um espaço onde a pluralidade surja a partir do reconhecimento e aceitação da singularidade de cada um e não de um conjunto de pessoas todas iguais.

Percebemos, desta forma, que as relações que estabelecemos com as crianças são muito mais decisivas que a influência que a mídia pode exercer sobre elas e sobre nós. E nas nossas relações com a criança há também o fato da criança lidar com o desenho, com a televisão, com as mídias digitais contemporâneas, com o mundo, privilegiando o entretenimento, mas não apenas divertindo por divertir-se. A criança se entretém explorando e agindo no mundo em que se insere, isto é no seu contexto e em condições objetivas dadas, tudo ao mesmo tempo; enquanto nós, adultos, tendemos a privilegiar os trabalhos utilitários e rentáveis, dicotomizando entretenimento e trabalho.

Por último, compreendemos que a Indústria Cultural está também presente nos desenhos animados chamados de "educativos" e que esta marcação é tão somente uma fantasia para se apresentar como tal, enquanto entrega a diversão pela diversão. Assim, não há sentido em diferenciarmos os desenhos como educativos e de entretenimento, pois ambos são instrumentos que suportam a condição de educativo. O importante, novamente, é estarmos presentes, participarmos daquilo que as crianças assistem pela televisão, cinema, internet e exercermos, com elas, uma reflexão que os relacione com o mundo que se apresenta na vida real.

Diante deste nosso entendimento final, é importante levarmos nossa compreensão às crianças e às instituições que participaram desta pesquisa, bem como ouvi-las em relação ao que compreendemos. A partir deste encontro, talvez abra a possibilidade de um estudo de projeto de um desenho animado com a participação das 
crianças; o que não foi possível neste trabalho. Por fim, precisamos ressaltar que as nossas percepções se confinam aos sujeitos da nossa pesquisa e inseridos no campo do nosso estudo.

\section{REFERÊNCIAS}

CAMPOS, M. M.. Por que é importante ouvir a criança? A participação das crianças pequenas na pesquisa científica. In: CRUZ, Silvia Helena Vieira. A criança fala: a escuta de crianças em pesquisas. São Paulo: Cortez, 2008.

CARNEIRO, V. L. C. Castelo Ra-Tim-Bum: o educativo como entretenimento. São Paulo: Annablume, 1999.

CARVALHO, A. M. A.; MÜLLER, F. Teoria e prática na pesquisa com crianças: diálogos com Willian Corsaro. São Paulo: Cortez, 2009.

CHARLTON, M. Hermeneutica Estructural del caso individual y conocimiento general a cerca del trato de los niños con los médios de comunicacion masiva. Tradução do alemão para espanhol de Martin Bruggendick. In: FILP, Johanna et al.(org.). Analisis cualitativo de interacciones sociales: introducción a la hermeneutica estrucutural. Santiago: CIDE, 1994a. Disponível em: http://biblioteca.uahurtado.... Acesso em: 20 jul. 2014.

CHARLTON, M. Introduccion a la Hermeneutica Estructural. Tradução do alemão para espanhol de Martin Bruggendick. In: FILP, Johanna; et al. (org.). Analisis cualitativo de interacciones sociales: introducción a la hermeneutica estrucutural. Santiago: CIDE, 1994b. Disponível em: http://biblioteca.uahurtado.cl/ujah/Reduc/pdf/pdf/7144.pdf. Acesso em: 20 jul. 2014.

CORSARO, A. W. Reprodução interpretativa e cultura de pares. In: CARVALHO, Ana Maria Almeida; MÜLLER, Fernanda. Teoria e prática na pesquisa com crianças: diálogos com Willian Corsaro. São Paulo: Cortez, 2009.

COSTA, P. J. F. S; FERNANDES, N; PEREIRA, M. B. O. Crianças investigadoras? Cenários de participação ativa na Educação Básica. Conjectura: Filos. Educ., Caxias do Sul, v.18, n. especial, p. 174-192, 2013.

CRUZ, S. H. V. A criança fala: a escuta de crianças em pesquisas. São Paulo: Cortez, 2008.

DELGADO, A. C. C.; MÜLLER, F. Abordagem etnográficas nas pesquisas com crianças. In: CRUZ, Silvia Helena Vieira. A criança fala: a escuta de crianças em pesquisas. São Paulo: Cortez, 2008.

DORNELLES, L. V. Infâncias que nos escapam: da criança na rua à criança cyber. Petrópolis: Vozes, 2008. 
FILP, J. et al. (org.). Analisis cualitativo de interacciones sociales: introducción a la hermeneutica estrucutural. Tradução do alemão para espanhol de Martin Bruggendick.. Santiago: CIDE, 1994. Disponível em:

http://biblioteca.uahurtado.cl/ujah/Reduc/pdf/pdf/7144.pdf. Acesso em: 20 jul. 2014.

FLICK, U. Desenho da pesquisa qualitativa. Porto Alegre: Artmed, 2009.

HEINZMANN, L. „Ich mache hier kaputt was ich will“ objektiv-hermeneutische analyse einer interaktion mit einem aggressiven kind. Tese (Doutorado em Piscologia). Freiburg 2005. Disponível em: https://www.phfreiburg.de/fileadmin/dateien/fakultaet1/psychologie/Uploads/wirtz/LisaHeinzmanngesamtDipl.pdf. Acesso em: 20 jul. 2014.

KRAIMER, K. Studienbrief 7: objektive hermeneutik. Alemanha: Wilhelm Fink Verlag, 2008. Disponível em: http://pt.scribd.com/doc/148157439/Ulrich-OevermannStudienbrief-7-Objektive-Hermeneutik-Delmenhorst-2000. Acesso em: 18 jun.2014.

MAROTZKI, W. Objektive hermeneutik (Ulrich Oevermann). Disponível em: http://www.uni-magdeburg.de/iniew/files/u4/lehre/07ss/Vorlesung_Methoden/06.pdf.

OEVERMANN, U. Klinische soziologie auf der basis der methodologie der objektiven hermeneutik: manifest der objektiv hermeneutischen sozialforschung. Frankfurt: IHSK, 2002. Disponível em:

http://www.ihsk.de/publikationen/Ulrich_OevermannManifest_der_objektiv_hermeneutischen_Sozialforschung.pdf. Acesso em: 07 jun. 2014.

REIS, M. A creche no trabalho... o trabalho na creche: um estudo do Centro de Convivência Infantil da UNICAMP trajetórias e perspectivas. 1997. Dissertação (Mestrado) -Universidade Estatual de Campinas, Campinas, SP. 1997.

REIS, M.; SANTOS, L.; XAVIER, M. do C. Crianças e infâncias: Educação, conhecimento, cultura e sociedade. In: REIS, M.; SANTOS, L.; XAVIER, M. do C. Crianças e infâncias: educação, conhecimento, cultura e sociedade. São Paulo: Annablume, 2012.

REICHERTZ, J. Objective Hermeneutics and Hermeneutic Sociology of Knowledge. In: FLICK, Uwe et al. (eds.). Companion to qualitative research. Londres: Sage, 2004. Disponível em: https://www.unidue.de/imperia/md/content/kowi/hermeneutikenglisch.pdf Acesso em: 01 jun. 2014.

SCOCUGLIA, J. B. C. A hermenêutica de Wilheim Dilthey e a reflexão epistemológica nas ciências humanas contemporâneas. Sociedade e Estado, Brasília, v. 17, n. 2, p. 249-281, jul./dez. 2002.

SPAREMBEGER, R. F. L. Bett x Gadamer: da hermenêutica objetivista a hermenêutica criativa. Revista da Faculdade de Direito da Universidade Federal do Paraná, Curitiba. 2005. Disponível em: http://www.estig.ipbeja.pt/ ac_direito/RaquelS.pdf. 
Acesso em: 02 jun. 2014.

VILELA, R. A. T. A análise sociológica "Hermenêutica Objetiva": novas perspectivas na pesquisa qualitativa. In: CONGRESSO BRASILEIRO DE SOCIOLOGIA, 15. 2011, Curitiba. Anais [...].Curitiba: GT: sociologia do conhecimento e abordagens qualitativas, 2011.

VILELA, R. A. T. A pesquisa empírica da sala de aula na perspectiva da teoria crítica: aportes metodológicos da hermenêutica objetiva de Ulrich Oevermann. In:

PUCCI, B.; COSTA, B. C. G; DURÃO, F. A. (org.). Teoria crítica e crises. reflexões sobre cultura, estética e educação. São Paulo: Autores Associados, 2012.

VILELA, R. A. T.; NAPOLES, J. N. A pesquisa sociológica "Hermenêutica Objetiva": novas perspectivas para a análise da realidade educacional e de práticas pedagógicas. In: REUNIÃO ANUAL DA ANPEd, 31., 2008, Caxambu-MG. Anais [...].Caxambu-MG: ANPED, 2008. Disponível em: http://31reuniao.anped.org.br/1trabalho/GT14-4741-Int.pdf. Acesso em: 01 jul.2014.

VILELA, R. A. T. Evidências empíricas do empobrecimento da experiência formativa na sala de aula do ensino médio. In: MORGADO, José Carlos; SANTOS, Lucíola Licínio de Castro Paixão; PARAÍSO, Marlucy Alves. Estudos curriculares: um debate contemporâneo. Curitiba: CRV, 2013.

VILELA, R. A. T.; NAPOLES, J. N. "Hermenêutica Objetiva" e sua apropriação na pesquisa empírica na área da educação. Linhas Críticas, Brasília, DF, v. 16, n. 31, p. 305-326, jul./dez. 2010.

WELLER, W. Aportes hermenêuticos no desenvolvimento de metodologias qualitativas. Linhas Críticas, v. 16, n. 31. Brasília. 2010.

WERNET, A. Hermeneutics and objective hermeneutics. FLICK, Uwe. The sage handbook of qualitative data analysis. London: Sage, 2013. 